https://www.journal-imab-bg.org

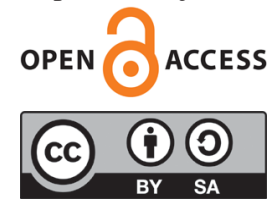

Review article

\title{
DENTURE ADHESIVES - IMPLEMENTATION AND ADVANTAGES
}

\author{
Nikolay Apostolov ${ }^{1}$, Rangel Todorov ${ }^{1}$, Bozhidar Yordanov${ }^{1}$, Mariana Dimova- \\ Gabrovska $^{1}$, Todor Peev ${ }^{2}$ \\ 1)Department of Prosthetic Dental Medicine, Faculty of Dental Medicine, \\ Medical University - Sofia, Bulgaria. \\ 2) Ex Deputy Rector of Medical University Sofia, Bulgaria, Private Practice - \\ Sofia, Bulgaria.
}

\section{SUMMARY:}

One of the main issues with complete dentures is their retention and stability while functioning. People would like to eat with their dentures on in a high-quality way, without having the feeling of the presence of a foreign body in their oral cavity. Another serious problem is the patients' discomfort when they are fitted with new complete dentures and the impeded adaptation to them. On the Bulgarian and world markets, there are a lot of products aimed at eliminating these problems. Some of them are denture adhesives, also called gules or denture fixatives. There is a widely spread opinion they help only in case the dentures are often disconnected and are poorly wrought, but both a large part of the patients and some dental, medical doctors are not well acquainted with the advantages and shortcomings of denture adhesives; the indications and contraindications to their application. In Bulgaria, the most widely adopted denture adhesives are Corega, Protefix, Dental, Oradey, etc.

Keywords: complete dentures, retention, stability, denture adhesives,

\section{INTRODUCTION:}

The retention and stability of complete dentures are subject to extensive scientific research in Bulgarian and foreign authors. Different approaches are recommended - a refinement of the impression technique, determination of the interocclusal relationship, order of the artificial teeth or use of elastic lining materials for better closure of the valve zone [1]. The knowledge of the different means providing retention, stability and comfort of the prosthetic restorations both in treatment of the adult patients and children is an important proof of the professionalism of the dental doctor [2, 3, 4]. When these methods cannot provide patient comfort and satisfy the objective assessment of the dentist [5] the use of dental adhesives has indicated. Application of denture adhesives, making the patient aware of their functioning, persuading the patient to use them, these are of major importance for the quality of complete-denture treatment.

\section{General Data on Denture Adhesives}

The first-ever denture adhesive was atented in 1913. There is documentation of the use of denture adhesives from 1923 and 1930 [6]. According to S. Yankell [7], up until 1939, there are data that 15 million had been using denture adhesives. Of all, means of retention of complete dentures, adhesives are most widely spread and least detrimental to health [8]. The improvement of stability and retention of complete dentures with the help of some adhesive was proven in 1975 . Other methods widely used today for the improvement of retention quality of complete dentures are implants or natural teeth that serve for the fitting of overdentures [1,9]. Apart from the term "denture glue" used in Bulgaria by B. Atanasov, other widely adopted terms are also "denture adhesive" [10] and denture fixative [11].

Denture adhesives are available on a large scale, non-toxic, soluble products, that are applied between the denture and the mucosal surface for the purpose of improving the retention, stability and function of complete dentures [12]. If used correctly, the adhesives can provide reliable estimations of the ability of the dental doctor for exact application of means of retention [13] and they can also comprise a useful part of the dental care for the patient [14]. Adhesives establish a connection, albeit a temporary one, between a denture and underlying tissues [15]. According to À. Flynn Arlene [16] they turn into a necessity for the patient exactly because they enhance that connection.

Research by A. Coates [17] in 2000 reached the conclusion that $52 \%$ of the patients do not feel any need of glue, $20.5 \%$ do not know what denture adhesive is and what it is used for at all, and $32.9 \%$ have tried using it, but only $6.9 \%$ continued using it. Research by M. Ozcan [6] in Istanbul reached the conclusion that somewhere between $7-33 \%$ of the patients with complete dentures use adhesives, but people, in general, are not well acquainted with their existence, advantages and methods of implementation. Research in Wales estimated that $12 \%$ of women and $10 \%$ of men use denture adhesives, but a 
large part of them start avoiding their usage due to the high price and the insufficient duration of action. There are certain requirements for the denture fixatives, and it is considered necessary for them to comply with those requirements [18]. Denture fixatives are required:

1) to maintain neutral $\mathrm{Ph}$ and not to induce the development of bacterial colonies, provided that it is proven denture adhesives (DA) do not allow the development of Candida;

2) to have minimal toxicity in relation to the oral mucosa since their minimal present cytotoxicity is proven;

3) to maintain the connection denture - denture space for 12 to 16 hours;

4) to be easy to clean from both the denture and the mucosa;

5) to taste good;

6) to be easy to find and at an affordable price. ditions

Denture glues can be used for different clinical con-

- cases with severe atrophy of the alveolar ridges and highly positioned frenulums, gingivobuccal connections, presence of movable mucosa

- acutely present reflexes for nausea and vomiting

- patients with systemic diseases (AIDS, Hotchkin Lymphoma, cancer, autoimmune diseases) and dysfunctions of the salivary glands

- cases of loss of different anatomical structures in the maxillofacial area [19].

- for achieving a prophylactic psychological effect in order to facilitate the adaptation to new complete dentures (CD) [20].

- for increasing the retention of immediate dentures

- for prevention of the development of denture stomatitis [22, 23].

- for temporary gluing of roots;

Of course, there are also contraindications to the use of denture adhesive: adhesive;

- in cases of allergy to a certain ingredient of the

- with immediate dentures where the glue helps the strong retention of the denture and the impeded removal can be traumatic to the post-extraction wounds;

- in cases of inappropriately wrought complete dentures where the faults in the making are the sole reason for the poor retention of the denture;

- patients with cardiovascular diseases. The powder fixatives contain Sodium, which is ingested when dissolved, and its increased concentration increases the blood pressure. In such cases, paste-like glues are recommendable as the solubility of sodium with them is minimal;

- in immunosuppressed patients;

- as an alternative to good clinical practice and skills.

\section{Types of denture adhesives and their chemical composition}

Denture adhesives can be divided into two large groups according to their action and chemical composition:

1)Soluble adhesives. They are also called temporarily adhering and are washed away with time by saliva with feeding, liquid ingestion, speech function. They are available as paste, cream, liquid or powder [24]. It is proven they are not detrimental to the soft tissue.

2) Insoluble adhesives. They are used for individual rebasing by the patient and are offered in the form of tissue or paper plaques impregnated with ingredients that increase adhesion. According to M. Boone [25], they have negative, resorbent action on the alveolar bone and hence, are not appropriate for mass application. Yet their use is recommended in cases of severe atrophy of the mandible as they help the "rebasing" in home conditions, and also increase the height of the occlusion between 1.2 and $1.7 \mathrm{~mm}$ [26].

Each of the glues contains one basic ingredient that leads to its swelling in contact with saliva and to the increase of its viscosity. In the past, these basic ingredients were the plant rubbers (acacia, karaya, tragacanth, xanthan) that were strongly water-soluble, and the mechanism of their retention was based on a nonionic reaction. However, they have certain shortcomings - their retention action is insufficient, sometimes they show proven allergizing effect and demineralizing action on the rigid tooth tissues present in the mouth. This lead to the development of basic synthetic ingredients used in contemporary adhesives. They are mixtures of strongly soluble (carboxymethyl cellulose, povidone) and weakly soluble (polyvinylmethyl ether/maleic anhydride) salts. The glues also contain a connecting ingredient - polyethylene-oxide, vaseline, polyethylene mineral oil (in pastes and crèmes), sodium phosphate, calcium silicate (in powders). There are also a number of additional ingredients: preservatives, surfactants, flavors (peppermint, peppermint oil, green tea), coloring agents (different dyes), spices, antibacterial agents (hexachlorophene, sodium borate and tetraborate, ethanol), antimycotic agents (hydroxybenzoate), fillers (magnesium oxide) [11]. Of course, there is also a small percentage of ingredients that are not announced in public and represent a trade secret.

According to the manufacturer, the composition of the product CoregaFix'n'Fàst Sensitive is as follows:

- 30\% poly (methylvimyl-ether/maleic acid) sodium-calcium mixture of salts;

- 29\% vaseline;

- 24\% Carboxymethylcellulose sodium;

- $17 \%$ mineral oil;

According to the manufacturer, the composition of Corega Cream (also known as PoliGripflavorfree, Super PoliGrip free, UltraCorega) is as follows:

- $17 \%$ mineral oil;

- 24\% Carboxymethylcellulose;

- $30 \%$ gantrez;

- 20\% harmless ingredients;

According to the manufacturer, the composition of 100 grams Protefixficative cream:

- gantrez - silicon dioxide; 
- carboxymethylcellulose - menthol;

- thick paraffin - azorubine;

- white vaseline - methyl-4-hydroxybenzoate.

\section{Correct application of denture adhesives}

For the normal action of denture adhesives, it is necessary to apply them correctly. The mouth cavity should be cleaned of any food remains or remains from a previous application of adhesive. The necessary quantity in case of paste application is 0,5-1,5 grams. Any excessive quantity would impair the action of the product. According to S. Ahila [27], the thickness of the layer applied should be minimal in order to provide normal retention. If the powder is used, it should be spread on the side of the denture facing the mucosa, and the excess powder should be dusted off. Most adhesives are applied on a preliminary cleaned and dried denture, but in cases of xerostomia, the denture is recommended to be slightly moistened. The paste is applied on the denture in the area of the incisors, the molars and on the palate (in cases of the complete upper denture) in small lines. Another option for application is to put the glue in dots at $5 \mathrm{~mm}$ distance between them. The denture is fit in the mouth and pressed by hand for $10 \mathrm{sec}$, and then the mouth should be opened and shut several times until central occlusion is achieved. That shall provide the appropriate thin layer of glue. The remains of the glue coming outside the denture should be cleaned with a kerchief. Here we have to note that once fit, and the glue should not be used for too long. The denture and the mouth should be cleaned from the fixative at least once a day $[20,28]$. If any difficulties with the taking off of the complete denture are experienced, one has to hold hot water in his/her mouth for a while.

\section{comfort}

IV. Influence of denture adhesives on the patient's

The lack of natural teeth affects in different ways the function of the masticatory system and the psyche of the patient. Most strongly affected are chewing and biting off, less influenced is speech and the least is the embarrassment due to the patient's appearance. According to G. Zarb [11], the most important role of complete dentures (CD) is the restoration of masticatory function. The relation that is most often looked after is the one of the qualities of the dentures, the anatomical-morphological specifics of the mouth cavity and the approval of the new dentures by the patient $[29,30]$. However, in the USA, the cases of dissatisfied and affected patients with complete dentures are above $10 \%$, and this share is growing. According to M. J. McEntee [31], it is no less than $60 \%$ of the dentures that are loose and unstable. Elderly people have lesser requirements to dental procedures, but nevertheless, they suffer from dental dysfunctions and in particular, from ineffective complete dentures. The same research works show that $71 \%$ of the people are satisfied with their complete dentures, but $29 \%$ experience certain dissatisfactions. When a patient with complete denture looks for dental help, his/her complaints are usually re- lated to an uncomfortable or unstable denture. Before the treatment, the completely toothless patients feel the need for complete dentures in order to improve their aesthetic appearance and masticatory function. After the dentures are made, those same patients increase their requirements to the dentures' retention and stability [32]. What makes patients use denture glues is the feeling of security, selfconfidence and comfort they provide. The adhesives are used mainly for improvement and enhancement of retention and stability of complete dentures and for increasing the biting strength of those dentures. The glues help improve the speech function, the sound articulation [35] and the stability of dentures during swallowing. They do not allow food to enter between the denture and the denture space. They reduce the probability for development of Candida colonies [24]. The adhesives reduce the resorption of the underlying tissues and the risk of the appearance of parafunctions like bruxism. The movement of the denture with regard to the underlying tissues in masticatory function is reduced by the use of a denture fixative. According to J. Grasso [9], this movement reduction in dentures is $0,9-1,3 \mathrm{~mm}$ vertically, and $0,2-0,5 \mathrm{~mm}$ horizontally (respectively, the movements are anterior, posterior and lateral). The feeling of security and stability creates the opportunity for the denture to be used in a way pretty much similar to the natural masticatory function [35]. According to W. Tarbet, the use of adhesives on patients of the unsatisfactory condition of the denture space leads to better masticatory function as compared to patients whose denture-space condition is satisfactory, but they do not use adhesives. In the past, glues were considered appropriate for use only for poorly wrought and hard to retain complete dentures, for dentures that needed rebasing. Nowadays, this opinion has changed. It is proven that adhesives must be used for every complete denture since they provide a function close to that of natural dentition [8]. It thus helps the patient overcome more easily the loss of all natural teeth, reduces the mucosal inflammation and achieves a medical-biological and psychophysical effect. The advantage of enhanced retention and stability of complete dentures, which has been observed in the use of adhesives, can be seen both in patients who use complete denture for the first time and in those who have older dentures [8].

According to D. R. Cagna [36], the optimal treatment with complete dentures includes introducing the patient to the denture adhesives as assistance and the prescription of appropriate glue for improvement of retention, stability, as well as for achieving a better feeling of the new dentures. It is extremely important for the patient to feel the stability of the denture and for its appearance to correspond to his ideas of aesthetics. There is not a single reason, not even hunger, capable of making the patient use the dentures if they are not comfortable and stable. The development of bad habits in the very beginning of denture use leads to an inability for normal and correct chewing and swallowing of food. Adhesives are recommended to the patient mainly in case he/she has higher requirements for the retention and stability of his/her den- 
tures [6]. Yet they are also used in order to eliminate psychic discomfort in patients with complete dentures, as a means of increasing the patient's trust in them [6]. Fixatives provide the feeling of psychic security and comfort in people wearing complete dentures. In patients, there is often fear of braking the dentures while feeding due to the action of the chewing muscles, the tongue and the lips. Psychoprophylactic effect is also achieved as a consequence of the retention, stability, chewing function and the adaptation of the soft tissues to the new denture. This provides a feeling of security in the patient. We have to note that a lot of the people treated with complete dentures take the decision of using glue by themselves without any prescription of a dental doctor. In their opinion, the retention and stability are thus better than without the help of an adhesive. In general, $75 \%$ of dental doctors recommend the use of some kind of denture adhesive.

It is extremely important to remove the pain of the new complete dentures since it prolongs the adaptation period by at least 5-10 days. According to G. Todorov, et al. [26] the most often encountered pathology of that kind is the decubitus ulcer on the alveolar ridge. The situation with the second fitting with dentures is different as the adaptation should last 6-12 days.

Denture adhesives assist the performance of masticatory function identical to that of patients with natural dentition. The research included the testing of 10 patients at an age between 48 and 85 , as well as 10 patients with natural dentition at an age between 39 and 66 who served as a control group. The research was made with the help of a magnetometer measuring the movement of the lower chaw. The magnetometer was connected to a computer analyzing the data. The patients chewed a dry apricot weighing 3 grams and a piece of white bread of the same weight. These are foods considered problematic for chewing with complete dentures. The patients were first tested without the use of adhesive, and then 4 hours after applying it. The researched adhesive was Fixodent. The control group had a far better masticatory function $-83,6$ chewing movements per minute, as compared to the group with complete dentures, but only under the condition, it had not used fixative. After its application, the difference decreased, and the results were equalized.

Denture adhesives can improve significantly the function of patients with complete dentures. That is proven by the research work of E. Aziz et al. [33]. They tested 15 completely toothless patients at an average age of 61.5 , with developed atrophy of the mandibular alveolar ridge. Three types of fixatives were researched Fittydent, Fixodent, SuperCorega, with the help of auditory (subjective) and acoustic (objective) method. The patients were first tested without dentures in their mouths, then 2 weeks after the fitting of their new complete dentures. They were first tested without glue, and then 2 hours after the application of a certain type of adhesive. According to the auditory method, the patients read aloud certain words containing certain sounds ( $\mathrm{s}, \mathrm{z}, \mathrm{sh}, \mathrm{ch})$ at the beginning of the word, in the middle of the word, and at the end of the word. The reading was recorded, and the record was later on listened to and analyzed. According to the acoustic method, a spectrogram was created, and the analysis was made by a computer. The adhesive Fixodent had the best effect since, after its application, $100 \%$ of the patients produced the sounds "s", "z", "ch", and $95 \%$ of them also the sound "sh". Without any adhesive, the production of these sounds was impaired.

The influence of saliva on the retention action of denture fixatives is researched by J. Kasperski et al. [22]. The purpose is to assess this influence in a condition of saturation of given adhesive with different quantities of artificial saliva (Mucinox). Four glues were used - Protefix, Protefix+Aloe, hypoallergenicProtefix, Corega. Silicon was put on the margins of the dentures imitating the soft tissues of the mouth, after which the dentures were fit on an artificial model. The glue was added $(4 \mathrm{~cm}$, applied at different places) as well as artificial saliva. The denture was pressed strongly for $5 \mathrm{sec}$, , and after that, it was pulled with a device specially constructed for the purpose of the research. Measurements were taken with a gnathodynamometer. Different quantities of artificial saliva were added. Best results were achieved with the combination of Protefix and 3 parts artificial saliva (the denture was severed from the model at $15,60 \mathrm{~N})$. Corega and Protefix+Aloe provided a bit worse results (severing from the model at $13 \mathrm{~N}$ ), and the worst retention action had the hypoallergenicProtefix - severing at the force of $8 \mathrm{~N}$. Interesting is the fact that Corega had the best retention action at the maximum quantity of artificial saliva (4 parts), while the action of Protefix weakened by $30 \%$ at 4 parts of artificial saliva. The practical conclusion of the research is that adhesives should be chosen individually, in compliance with the specific characteristics of the patients and the quantities of their saliva.

It is proven $[34,35,36,37]$ that the positive effect of denture glues on masticatory function and the action of chewing muscles.

\section{CONCLUSION}

1. Dental adhesives can be used as a method of choice in the prophylactic treatment of totally toothless patients with complete dentures.

2. The use of a dental adhesive has a significant effect on the length of the mouth, both the upper and lower complete dentures and results in a significant increase in maximum bite strength.

3 . The use of a dental adhesive allows the development of upper palatal-reduced complete dentures in patients with a nausea reflex available. 


\section{REFERENCES:}

1. Yankova M, Yordanov B. [Application of elastic dental materials to patients with partial and total edentulism.] Infodent. 2014 Jun;15(4139):3-11. [in Bulgarian] [Internet]

2. Yordanov B, Yankova M, Yoncheva I. [Assessment the quality of life in patients with removable dentures, lined with soft elastic materials - a pilot study.] Infodent. 2014 Jun; 15(4-139):37-45. [in Bulgarian] [Internet]

3. Dimitrova D. [Fixed prosthetic treatment in childhood - functional aspects.] [dissertation]. Medical University - Varna; 2018. 189 p. [in Bulgarian]

4. Dimitrova D. Questionnaire survey of removable prosthetic treatment in children. MedInform 2019; 6(1):980-986. [Crossref]

5. Dimitrova D. Study of patient satisfaction with prosthetic treatment. MedInform. 2018; 5(3):914-919. [Crossref]

6. Ozcan M, Kulak Y, Ariran A, Silaitar R. The attitude of complete denture wearers towards denture adhesives in Istanbul. $J$ of Oral Rehabilitation. 2004 Feb;31(2):131-4. [PubMed]

7. Yankell S. Overview of research and literature on denture adhesives. Compend Contin Educ Dent 1984; Suppl 4:S18-21. [PubMed]

8. Psillakis J, WrightR, GrbicJ. In practice evaluation of a denture adhesive using gnathometer. J Prosthodont. 2004;33:244-50. [PubMed]

9. Grasso J, GrayT, Rendell J, Baker R. Effect of denture adhesive of retention of the mandibular and maxillary dentures during function. J Clinical Dent. 2000;11(4):96-103. [PubMed]

10. Atanasov B. [Dental problems of the adult population. Need preparations for dentures. Hygiene, prophylaxis and treatment of the oral cavity - second edition.] Auto Spectrum. 2002; 624. [in Bulgarian]

11. Jagger D, Harison A. Denture fixatives - an update for general dental practice. Br Dent. J. 1996; 180(8):310-311. [PubMed]

12. Zarb GA, Bolender CL, Eckert SE, Fenton AH, Jacob RF, MericskeStern R. Prosthodontic Treatment for
Edentulous Patients: Complete Dentures and Implant-Supported Prostheses 12th Edition. Mosby. September 17, 2003. [Internet]

13. Musani S, Dugal R, Kothavade M. A Review Of Denture Adhesives Used In The Dental Profession Ann essence dent. 2010 Jul-Sep;2(3):129133. [Internet]

14. Pophristova S. [Application of adhesives in removable dentistry. ] Infodent. 2003 Sep;8-10. [in Bulgarian]

15. de Baat C, van't Hoff $M$, van Zegnebroeck L, Ozcan M, Kalk W. An international multicenter study on the effectiveness of a denture adhesive in maxillary dentures using disposable gnathometers. Clin OralInvest. 2007 Sep;11(3):237-43. [PubMed]

16. Flynn Arlene A. Handbook of Nonprescription Drugs. 10th edition. Am Pharmaceutical Assoc. The national professional sociality of pharmacists.

17. Coates A. Usage of denture adhesives. J Dent. 2000 Feb;28(2):13740. [PubMed]

18. Kim E, Driscoll C, Minah G. The effect of denture adhesive on the colonization of Candida Species in Vivo. J Prosthodon. 2003 Sep;12(3): 187-91. [PubMed]

19. Pingo MA, Funk JJ. Augmentation of obturator retention by extension into nasal aperture: A clinical report. J Prosthet Dent. 2001 Apr;85(4): 349-351. [PubMed]

20. Spiechowicz E. Prosthetics. PZWL, Warsaw; 2004:197-201, 282 287.

21. Chowdhry P, Phukela SS, Patil $\mathrm{R}$, Yadav H. A study to evaluate the retentive ability of different denture adhesive materials: An in vitro study. $J$ Indian Prosthodont Soc. 2010 Sep;10(3):176-181. [PubMed]

22. Kasperski J, Chladek G, Zmudzki J, Lipski T. The effect of saturation by artificial saliva on the effectiveness of denture adhesives. Arch Mat Sceni Eng. 2011; 51(1):25-32.

23. Makihira S, Nikawa $\mathrm{H}$, Satonobu SV, Jin C, Hamada T. Growth of Candida Species on Commercial Denture Adhesives in Vitro. Int J Prosthodont. 2001 Jan-Feb;14(1):48-

\section{2. [PubMed]}

24. Nesreen El-Mekawy, Gomaa A, Habib A. Comparison of three different forms of denture adhesives: Direct measurement of denture retention and, study of patient satisfaction. EDJ. 2012. 58(3):1-9.

25. Gounder R. Sathasivam P. Importance of denture adhesive in complete denture patients- A review. Int J Rec Adv Multidis Res. 2016 Jun;3(6): 1535-7.

26. Shamsolketabi S, Nili M. The effect of denture adhesive on the efficiency of complete denture in patients with different alveolar ridges. Dent Res $J$ (Isfahan). 2018 Jul-Aug;15(4):271275. [PubMed]

27. Todorov G, Hristov S, Aleksandrov S. [Comparative study of prosthetic adhesives in the form of cream and pads "Fittydent".] Scientific Session - Plovdiv, 2012, Series D, XIII;2013:268-270. [in Bulgarian]

28. Ahila SC, Kumar BM, Vasanthakumar M. Mystery of denture adhesives: A literature review. SRM Univ J Dent Sci. 2011 Jun;2(2):112-7.

29. Bogucki ZA. Clinical aspects of the use of dental adhesive materials in patients with chronic xerostomia. Gerodontology. 2013 Jun;30(2): 162-6. [PubMed]

30. van Aken AA, de Baat C, van Rossum GM, Mulder J, Kalk W. ["Prosthetic Condition" and Satisfaction With Dentures] [in Dutch] Ned Tijdschr Tandheelkd. 1995 Jan;102(1):12-4. [PubMed]

31. Wolff A, Gadre A, Begleiter A, Moskona D, Cardash H. Correlation Between Patient Satisfaction With Complete Dentures and Denture Quality, Oral Condition, and Flow Rate of Submandibular/Sublingual Salivary Glands. Int J Prosthodont. 2003 JanFeb;16(1):45-8. [PubMed]

32. MacEntee MI, Prosth D. The Complete denture: A Clinical Pathway. 1/E edition. Quintessence Pub Co. January 15, 1999.

33. Mazurat NM, Mazurat RD. Discuss Before Fabricating: Communicating the Realities of Partial Denture Therapy. Part I: Patient Expectations. J Can Dent Assoc. 2003 Feb;69(2):904. [PubMed] 
34. Adel Aziz E, Adel Aziz A, Eldeen Ibrahim DE, Mohammed Ahmed AE. Comparative study between different denture adhesives in improving phonation in complete denture wearers. J Am Science. 2010; 6(11):556-561.

35. Cagna DR, Massad JJ. Prosthesis retention and effective use of denture adhesive in complete denture therapy. dentalcare.com. June 3, 2010. [nternet]
36. Peev T, Filchev A. [Clinic of prosthetic dentistry]. Sofia. 2016: 152. [in Bulgarian]

37. Damyanov N, Peev T. [Etiology, diagnosis and treatment of temporomandibular disorders.] Zabolekarskipregled. 2006; 2:195-142. [in Bulgarian]

38. Todorov B, Peev T. [Shortened method for measuring of vertical dimension in prosthetic treatment with removable acrylic dentures.] Stoma- tologia. 1975; 58(4):293-296 [in Bulgarian]

39. Ralev R, Kisiov A, Aleksieva K, Peev T. [Material and methods for individual trays.] Stomatologia. 1978; 60(2):132-136. [in Bulgarian]

40. Likov Ch, Aleksieva K, Peev T, Papazian E. [Influence of the polymerization mode on the mechanical characteristics of the "Superacryl N".] Problems of Stomatology. 1981; IX: 72-78 [in Bulgarian]

Please cite this article as: Apostolov N, Todorov R, Yordanov B, Dimova-Gabrovska M, Peev T. Denture Adhesives Implementation and Advantages. J of IMAB. 2020 Apr-Jun;26(2):3177-3182.

DOI: https://doi.org/10.5272/jimab.2020262.3177

Received: 29/06/2019; Published online: 05/06/2020

\author{
Address for correspondence: \\ Nikolay Apostolov \\ Department of Prosthetic Dentistry, Faculty of Dental Medicine, Medical \\ University, Sofia, \\ 1, St. G. Sofiiski Blvd.,1431 Sofia, Bulgaria. \\ e-mail: nickogl@abv.bg,
}

